\title{
Big GAAP/Little GAAP: Will The Debate Ever End?
}

Gail B. Wright, FGCU, Fort Myers, Florida, USA

Daniel Fernandez, FGCU, Fort Myers, Florida, USA

Jeremy Burns, LarsonAllen, Fort Myers, Florida, USA

Ryan Hawkins, SVA, Madison, Wisconsin, USA

Christina Hornsby, Hill, Barth, \& King, Naples, Florida, USA

Sunny Patel, Goal Financial, Alexandria, Virginia, USA

\begin{abstract}
There has been an ongoing debate for decades, especially since the inception of the Financial Accounting Standards Board (FASB), over the appropriate application of generally accepted accounting principles (GAAP) to private companies. This so-called 'Big GAAP vs. Little GAAP' debate has now come to a crisis point. The Financial Accounting Foundation (FAF) has taken a position that is contrary to the recommendations of the Blue Ribbon Panel on Standard Setting for Private Companies (the Panel) presented in January 2011, despite having been represented on the Panel. The American Institute of Certified Public Accountants (AICPA), also represented on the Panel, has responded by taking a strong stand in favor of the Panel's position and against the new FAF recommendation and Invitation to Comment, published on October 4, 2011. Additionally, the International Accounting Standards Board has developed a set of reporting standards for small and medium size enterprises (IFRS for SMEs) that has not been recognized in the US. In this paper, we examine the history of the Big GAAP/Little GAAP debate in the US and internationally. We find substantial support for reducing requirements of private companies and recommend that International Financial Reporting Standards for Small to Medium-Sized Enterprises (IFRS for SMEs) be used for public companies of all sizes to be consistent with standards that have been accepted globally.
\end{abstract}

Keywords: Big GAAP; Little GAAP; IFRS; Financial Accounting Foundation

\section{INTRODUCTION}

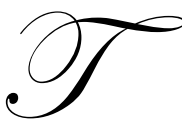

he debate regarding the appropriate application of accounting standards has been a topic of discussion and study for decades. In recent years, with the proliferation of standards by the Financial Accounting Standards Board (FASB), the debate has become one of standards overload. This so-call 'Big GAAP vs. Little GAAP' debate has now come to a crisis point. The Financial Accounting Foundation (FAF) has taken a position that is contrary to the recommendations of the Blue Ribbon Panel on Standard Setting for Private Companies (the Panel), despite having been represented on the Panel. The American Institute of Certified Public Accountants (AICPA), also represented on the Panel, has responded by taking a strong stand in favor of the Panel's position and against the new FAF recommendation and request for comment published on October 4, 2011. Additionally, the International Accounting Standards Board has developed a set of reporting standards for small and medium size enterprises (IFRS for SMEs) that has not been recognized in the US.

Those who desire to reduce the reporting requirements of private enterprises in the US (or smaller enterprises in the international arena) argue that only information that is relevant to decision makers should be required and the cost of implementing standards for providers of financial statements should be less than the benefits they provide to users. The most common arguments of those who support a single GAAP for all enterprises rely on comparability between and within companies and the general acceptance of existing standards. They fear that change could bring confusion. 
In the following sections we will present the history of the debate in academic and practitioner journals. We will discuss the studies that have been undertaken, especially by the AICPA and the FASB, to provide clarity to the issues surrounding the Big GAAP/Little GAAP argument. We present the solutions reached in other countries and within the International Financial Reporting Standards (IFRS) framework. Finally, we provide insight into the differences between the path taken by the FAF and the AICPA and the differences between approach proposed in the US and the IFRS for small-medium enterprises. We conclude with recommendations for resolution and suggest areas for future studies.

\section{A HISTORICAL PERSPECTIVE}

\section{The Basis for Debate}

Even before the FASB had written its first standard, a debate had begun on issues surrounding the continued application of a single set of GAAP standards for all companies, both public and private. While more than 15,000 public companies must follow GAAP in order to sell their securities on US exchanges, more than 28 million private entities are currently required to follow the same standards, despite the fact that they do not sell securities and their most important external users are their lenders, primarily banks. While individual requirements considered onerous to private enterprises have been identified in studies and from practitioner experience, the essence of the debate for private entities revolves around two characteristics: relevance of information required and cost to the provider vs. benefits to the user.

Statement of Financial Accounting Concepts (SFAC) \#2 discusses the qualitative characteristics of financial accounting information that make information useful to decision makers. Relevance is one of the two fundamental qualitative characteristics. Accounting information is relevant if it is capable of making a difference to a decision maker. Information is relevant if it has predictive value and if it confirms or corrects prior information. To be relevant, the information must be material to a particular enterprise. SFAC \#2 does not contemplate that an enterprise will present irrelevant information as that might cloud the decision process.

Cost vs. benefit is identified as a constraint to providing financial information. It is presumed that the benefits of providing the decision maker with information will outweigh costs to the information provider. In terms of the Big GAAP/Little GAAP debate, it has been argued that the cost of meeting all GAAP standards exceeds the benefits that users of private company financial statements derive. The conclusion from those desiring a change to requirements for private enterprise financial statements: certain required standards that are complex, costly, and irrelevant to users of private company financial statements and therefore should not be required.

The arguments from those who support maintaining the current single-GAAP system rely on acceptability and comparability (Herman, 2010). GAAP is the gold standard in accounting principles and standards because it has been accepted by preparers, practitioners and users, especially securities markets. Acceptance means there is a universal way of measuring the value of companies that has been found useful by all groups.

SFAC \#2 identifies comparability as an enhancing quality associated with both relevance and faithful representation. Comparability allows for analysis of similarities and differences in events that occur to different entities. Additionally, comparability includes consistency, which is the ability to analyze a company across time because financial information is presented in a consistent manner, using the same set of principles.

Proponents of a single-GAAP argue that allowing exceptions to GAAP for private companies would dilute acceptance and weaken the current system. Development of a separate GAAP for private entities would not only dilute acceptance but also confuse all groups about what is acceptable in the circumstances. Essentially, two sets of standards would have to be learned and a choice of correct application of GAAP be made. Additionally, whether exceptions or a 2-GAAP system were employed, the ability to compare companies, specifically when the comparison is between a public and a private enterprise would be negatively affected. 


\section{Observations Regarding Change}

In 1972, two issues were cited by experienced practitioners as being contrary to the interests of private entities: a requirement to list all items of noncompliance with GAAP (McGill, 1972) and the cost of providing information in financial statements that were of little value to the private enterprise (Arnstein, 1972) according to Zanzig and Flesher (2006). In 1974 and again in 1977, Max Block, editor of The CPA Journal, proposed dual accounting standards for public and private companies, according to Zanzig and Flesher, (2006).

While these authors were expressing concerns based on client positions or personal perspectives, Falk, et al., (1976) surveyed closely held companies to determine what information was relevant and what was not. They found that earnings per share, price level adjustments and segment reporting were not important measures for private companies. These items, required of public companies at the time, were not considered relevant to users of private company financial statements. They also reported that balance sheet information was more relevant than income statement information to the same users. J. E. Campbell (1984) added deferred taxes to the growing list of information required of public companies but not considered relevant by users of private company financial statements.

Zanzig and Flesher (2006) used a list of 12 GAAP requirements identified by the AICPA's Private Company Financial Reporting Task Force to study perceptions of significance. More than 3,500 respondents in three groups, owners/managers, external stakeholders (users), and practitioners, completed the survey. External stakeholders included creditor/lender, investor/venture capitalist, and surety/bonding entities. Zanzig and Flesher found that two items considered to be complex, comprehensive income and fair value accounting for assets and liabilities, were very important to all users. (The finding that external stakeholders value comprehensive income and fair value accounting contradicts the results of other studies and may be biased by the inclusion of investor/venture capitalists for whom this information is relevant in public companies or companies that may become public.) Lenders and bonding entities considered deferred income taxes and guarantees to be very important. Only practitioners believed that postretirement and retirement plans, leases, intangibles, and variable-interest entities were important. None of the three groups believed that share-based payments were relevant.

Stahlin (2011) points out that relying on a single GAAP for all entities is a false choice because one size does not fit all entities. He cites the lack of relevance and the complexity of some standards to private companies as the reason behind the decision of some enterprises to accept a qualified opinion rather than to incorporate all information necessary to receive an unqualified opinion. Further, Stahlin states that some of the most complex standards are the most costly to implement. Complexity, in this situation, can be interpreted as an ingredient of the cost vs. benefits constraint from SFAC \#2 because private companies seldom have employees with the expertise required to prepare these measurements.

Love (2011) argues in favor of changing the single GAAP system based in part on changes in perspectives about equity securities. He states that markets have come to view equity securities of public companies as a trading medium rather than an investment vehicle. In this universe, exit value is the most important information to be gleaned from financial statements and exit value relies on fair value rather than historical cost.

Love finds that information that is relevant is different for private companies to demonstrate to lenders and vendors their ability to meet obligations than the information requires of public companies. He suggests that the information used to gauge debt repayment includes cash flow, capital, and collateral. In addition, he suggests that owners of private companies are more interested in the return on their investment than a return calculated on the basis of the fair value of the company's assets.

With regard to SFAC \#2, Love states that it is relevance, not comparability that should guide the GAAP applied to a private enterprise. To support his argument, he wonders why a user would compare a public company to a private company, given that investment in a private company might not be an option.

The opposite case is made by Naus (1974) who supported the single GAAP approach. He argued that alternative treatments could weaken fair presentation and full disclosure. Further, a single-GAAP approach is 
preferable because a private company may interact in the public environment by comparing itself to public competitors or perhaps by becoming a public company at some later date.

Grusd (2006 and 2011) is a proponent of maintaining the current single GAAP approach. His argument opposing a modified GAAP or 2-GAAP presentation has the following components: a single set of standards should apply to all entities, both public and private, because the list of many/most of the complex standards not applicable to private companies is limited and therefore cannot be onerous. He also suggests that formal acceptance of exceptions for private companies could be the beginning of a slippery slope effect that would erode GAAP as we know it for all companies, both public and private.

Grusd cites examples from his personal experience as a banker. In direct discussions with private company managers seeking loans, he has waived presentation of certain items the borrowing company claimed were too costly to include in financial statements they provided as the basis for a loan. He states that other lenders can make similar exceptions to GAAP requirements on a case by case basis and therefore no formal adjustment to the single GAAP framework is needed. Following this logic, acceptability of GAAP would be decided by each lender.

The debate over reporting for small enterprises is not limited to the US. Jamal et al. (2009), as part of their commentary on the exposure draft to create a separate GAAP for private entities in Canada, identified five principles that should be part of GAAP for private entities. The five principles were:

- $\quad$ Recognition and measurement based on historical cost;

- $\quad$ Separation of operating activities from financial activities;

- $\quad$ Centrality of operating earnings measurement;

- $\quad$ Balance sheet valuation derived through conservatism; and

- $\quad$ A proprietorship perspective that limits owners' equity to common stock only and where all other claims, including preferred stock, are classified as liabilities.

The authors, who were members of the American Accounting Association Financial Accounting Standards Committee, support the view that standards for private companies. These standards must be based on a new conceptual framework both for Canada and the US. Thus, the principles the authors describe as the basis for private entities differ significantly from the current Canadian Institute of Chartered Accountants (CICA) GAAP framework and US GAAP. They would eliminate fair value accounting and comprehensive income while relying on a "lower of cost or market" approach to the balance sheet for private companies. The authors suggest that disclosure limited to citing their existence should replace measurement for such complex items as pension plans for private enterprises. This framework supports the Canadian 2-GAAP approach.

\section{Studies Conducted on the Single GAAP System}

Studies have been conducted by the AICPA or supported by FASB over more than 30 years. One of the first studies, Report of the Study on Establishment of Accounting Principles, by the AICPA ("Wheat Report") was done in 1972, pre-dating the formation of FASB. Many studies were conducted over the next 23 years with early studies seeming to find support for the single GAAP approach. Abdel-Khalik (1983), for example, found that lenders and creditors favored the single GAAP approach for all entities because the information for their decisions was the same regardless of the enterprise type. More recent studies have raised concerns or have come to different conclusions.

In 1995, the AICPA Private Companies Practice Executive Committee identified standards overload as a serious problem facing private entities. By the end of 1995, after 22 years, FASB had issued 124 standards, some of which had been revised or set aside, compared to 30 Opinions issued by its predecessor, the Accounting Principles Board (APB) in its 14 year history. The ever-changing landscape of FASB standards can be seen as another aspect of complexity and higher costs, especially to private companies that do not have employees with accounting expertise. 
The AICPA produced the Private Company Financial Reporting Task Force Report, ("Castellano Report") in 2005. The user community that participated in this study, consisting of banks, venture capitalists, and surety companies, found support for a 2-GAAP framework citing as their main concern the issue of relevance. Over the next three years, the AICPA and the FASB formed joint study groups and task forces to review and examine the concerns of privately held companies. These efforts culminated in the Blue Ribbon Panel on Standard Setting for Private Companies (the Panel) formed jointly by the AICPA, FASB, and FAF in 2009. conclusions:

The Panel submitted its report to the parent organizations in January, 2011. The report contained two key

- $\quad$ A separate board should be established under FAF to develop reporting standards for private companies; and

- $\quad$ Changes should be made to existing standards for private companies and should be included in FASB's codification of GAAP.

If accepted, the relationship among the AICPA, FASB, and FAF would be radically changed (see Illustration 1). A board would be created with support from practice (e.g., AICPA and National Association of State Boards of Accountancy (NASBA)) to promulgate standards for private companies that would be co-equal with the Financial Accounting Standards Board and the Government Accounting Standards Board under the Financial Accounting Foundation.

FAF rejected the Panel's recommendations in an Invitation to Comment (October 2011). Instead of coequal boards in a 2-GAAP approach, the FAF decision is to create a Private Company Standards Improvement Council (PCSIC) with $11-15$ members and a chairman appointed by FAF from the members of the FASB. FAF gave the following charge to the Council:

- To develop criteria to determine when and whether exceptions to US GAAP should be made for private companies; and

- $\quad$ To review existing GAAP for exceptions or modifications for private companies.

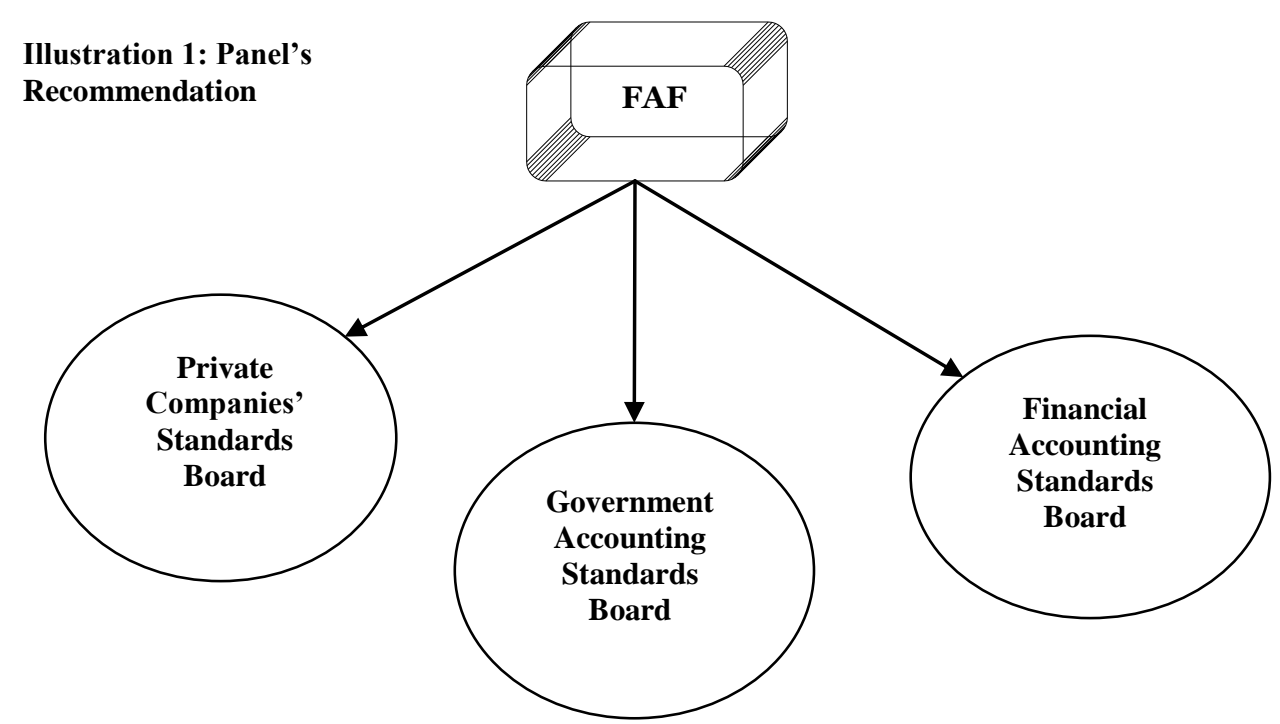

The AICPA responded very strongly, following the FAF's decision to not accept the Panel's recommendations,. The AICPA Council voted to consider "all options" to alleviate the burden on private companies if the FAF did not withdraw its proposal for a new committee and accept the Panel's recommendations. Ultimately, NASBA accepted FAF's revision. 


\section{INTERNATIONAL PERSPECTIVES}

There is no unified position regarding financial accounting standards in the global community. However, in the international arena, the debate over Big GAAP/Little GAAP is not limited to public vs. private companies Little GAAP, however defined, can be applied to small and medium public companies. Accounting standard setters in certain countries make the distinction for exceptions or a 2-GAAP approach based on company size. Size may be a specific cut-off number for revenue or total assets or it may reflect the number of types of users who may reasonably be expected to rely on financial statements. Australia is an example of the latter approach.

Some international researchers argue that unified compliance with one set of standards will lead to a balanced view since companies of different sizes will use the same standards. Carsberg, et al., (1985) argued that a distinction among companies according to size would involve an arbitrary cut off that would be hard to defend. Others view the debate from the point of stewardship. They believe that there could be a different true and fair view for small and large companies.

Stewardship is a strong influence in the UK, Canada, and several other countries. This concept refers to the owners' evaluation of management, assessing their success in achieving organizational objectives (Arnold, et al., 1994). While owners and managers of large companies are often separate, they are typically one and the same for small companies. If there is no separation between ownership and management, then the small business enterprise is unduly required to produce more detailed and cumbersome financial statements even though they don't have outside investors.

Previously, companies in the UK were governed by universal financial reporting and disclosure standards. The Companies Act of 1985 was the beginning of separate regulation for small entities. In recent years further changes have been made by the Financial Reporting Standard for Smaller Entities (FRSSE) that instituted abbreviated accounts and exemption from the statutory audit.

Businesses identified by the Companies Act of 1985 as being of a smaller size could now elect to use the FRSSE approach, adopting the abbreviated reporting. In the case of an audit exemption, the definition of small and medium sized companies conforms to the Companies Act with the exception of lower value of assets, number of employees, and turnover threshold.

Ireland, where the differential reporting debate was also ongoing, adopted the FRSSE. Much like the UK, Ireland seeks to reduce the accounting burden on smaller companies by allowing them to file abbreviated accounts. Although the small company must still prepare and distribute accounts to shareholders, these financial statements may be modified by disclosing fewer details than is required for larger companies (McAleese 2000).

Canada debated changing the single GAAP approach as well. Their reasoning was based on the fact that private company financial statements are prepared mainly for taxation and borrowing rather than for financial markets, even those of small and medium enterprises (SMEs) that are public companies. In addition, there are very few users of financial statements of small-medium enterprises (SMEs), with only owners/managers, bankers, taxation authorities, and perhaps venture capitalists who populate the user category. Therefore, Canadian standards that required SMEs to report according to big GAAP, are costly to comply with and overly complex. These costs include hiring professionals to prepare financial reports and continuing education for professionals. The result: overall cost of SME financial reporting continues to increase. Revising the standards to require a shorter and simpler form of reporting reduced the burden of producing SME financial statements.

To address the question of differential reporting of public companies and SMEs the Canadian Institute of Chartered Accountants' (CICA) undertook an examination of three alternative models:

- $\quad$ A single set of GAAP without exclusions;

- $\quad$ Two sets of GAAP (Big GAAP and Little GAAP); and

- $\quad$ A single set of GAAP with exclusions from certain standards for SMEs. 
The CICA believed the first alternative, a single set of GAAP without exclusions, should not be used and is not an acceptable option for the SME financial reporting stakeholders. Some research supported this position that SMEs tend to be smaller and have fewer resources than public corporations, making it relatively more costly to comply with GAAP (Feltham and Mathieu 2000a).

The second alternative model, a 2-GAAP approach, was considered but soon rejected as a possible solution. This model would have emphasized Big GAAP financial reporting for corporations that raise capital on the international markets and have complex transactions and disclosure requirements. Little GAAP financial reporting would require that SMEs use simplified standards that are not included in Big GAAP requirements. Due to the large variation of reporting requirements between the two methods, the CICA determined that the standards would be dissimilar. As a result, the CICA believed that this would lead to confusion and discredit the image of the profession.

The CICA proposed and adopted the third model: a single set of GAAP with exclusions from certain standards for SMEs. In this alternative, the SMEs are required to prepare financial statements based on standardized accounting rules. The CICA will allow exemption for entities qualifying as SMEs from implementing accounting rules that do not meet their needs or the needs of users of their financial statements. The primary rationale for these exclusions was to reduce SMEs compliance burden (Feltham and Mathieu 2000a).

Other nations have considered or implemented their own version of the alternative models reviewed by the CICA. New Zealand has adopted a set of GAAP with exemptions for SMEs. The new standards were published by the Institute of Chartered Accountants of New Zealand in 1997 as "Framework for Differential Reporting." The framework provided guidance on the available exemptions for SMEs, indicating exemptions from a statement of cash flows, accounting for income tax, and segment reporting. The Institute of Chartered Accountants, New Zealand (ICANZ) reasoned that the costs and benefits of complying with the financial reporting standards justified moving to a differential reporting system. More recently, New Zealand and the UK are proposing a 3-tiered GAAP to meet these needs.

Australia has implemented a hybrid method similar to using a single set of GAAP with exclusions from certain standards for SMEs (Big GAAP and Little GAAP). The new method, defined as the Reporting Enterprise Concept, was introduced by the Australian Accounting Research Foundation. The Australian Accounting and Reporting Foundation (AARF) found that general-purpose financial statements are utilized by external users who depend on financial statements for decision-making. Businesses entities that do not adhere to this definition are permitted to prepare financial statements according to an appropriate disclosed basis of accounting. This approach appears to be similar to the use of the Other Comprehensive Basis of Accounting (OCBOA) recommended in the US to address differences between entities. In Australia, these entities are required to provide an assurance report that complies with audit standards for these reports.

Table 1 summarizes the current status of the debate for the countries discussed above. Currently, the UK and Ireland are reviewing their standards to bring them into conformity with IFRS for SMEs. The United States is the only major country that is clinging to the 'one size fits all' single set of GAAP standards.

Table 1 Status of Adoption: Standards for SMEs

\begin{tabular}{|l|c|c|c|}
\hline \multicolumn{1}{|c|}{ Country } & Single GAAP & GAAP with Exceptions & 2-GAAP \\
\hline United States & $\sqrt{ }$ & $\sqrt{ }$ \\
\hline Canada & & $\sqrt{ }$ & $\sqrt{ }$ \\
\hline EU \& EEA & & & $\sqrt{ }$ \\
\hline UK (current) & & & $\sqrt{ }$ \\
\hline Ireland (current) & & $\sqrt{ }$ \\
\hline New Zealand & & & \\
\hline Australia & & & \\
\hline
\end{tabular}




\section{INTERNATIONAL FINANCIAL REPORTING STANDARDS (IFRS)}

The FASB and the IASB have been working together to create one set of generally accepted accounting standards for many years. The integration of US GAAP with International Financial Reporting Standards continues apace. In the meantime, the IASB has written standards which simplify the reporting required for SMEs (IFRS for SMEs, 2009). Acceptance of the simplified standards is growing in Canada and the EU/EEA countries.

As of 2002, countries of the European Union (EU) and members of the European Economic Area (EEA: Iceland, Lichtenstein, and Norway) adopted the IFRS promulgated by the International Accounting Standards Board (IASB). These standards were to be implemented no later than 2007 and incorporated a 2-GAAP approach in 2009, having adopted a separate set of standards for SMEs (IFRS for SMEs).

IFRS for SMEs is a stand-alone set of accounting and reporting standards that contains simplified reporting and disclosure requirements based on a cost-benefit analysis of the financial reporting needs of companies that are non-publicly accountable. Application of IFRS for SMEs relies on the non-publicly accountable criteria since there is no specific parameter to describe the size of an SME. This criteria would appear to rule out public SMEs based on the definition of public accountability: A company has public accountability if: (1) its debt or equity instruments are traded in a public market or it is in the process of issuing such instruments for trading in a public market, or (2) it holds assets in a fiduciary capacity for a broad group of outsiders as one of its primary businesses (Fitzpatrick and Frank, 2009). Based on the construct of non-public accountability, IFRS for SMEs appears to apply only to private enterprises. It is not applicable to non-profit or governmental entities.

IFRS for SMEs incorporate such basic principles as comparability, going concern, and materiality as part of their framework. Seifert and Lindberg (2010) report that these standards omit earnings per share, interim reporting, segment reporting and does not include the category "assets held for sale" on balance sheets. Investment property is reported according to its use rather than a policy that requires either cost or fair value. However, a full set of financial statements, including a statement of financial position, statement of comprehensive income, statement of changes in equity, statement of cash flows and notes with a summary of significant accounting policies is required.

The statistics for SMEs worldwide are staggering. More than $95 \%$ of all companies meet the criteria to use IFRS for SMEs. There are 28 million private sector enterprises in Europe and also in the US. The UK has 4.7 million while Brazil has more than 6 million enterprises that can use IFRS for SMEs. These numbers alone support the need for a simplified set of standards that will meet users' needs while controlling costs for SMEs.

Love (2010) opposes accepting IFRS for private companies for US GAAP. She argues that "users of private companies' financial statements are more than capable of adapting to full IFRS, which is already simpler than U.S. GAAP." We believe this argument is flawed. The argument does not consider costs to SMEs of complying with current GAAP or the complete IFRS. The argument does not consider the need for expertise or costs to SMEs to transition to new standards that are more than what is relevant. Finally, Love bases her argument on the perspective of users rather than considering the needs of SMEs.

\section{RECOMMENDATIONS}

The issues for US standard setters center on relevance - the needs of users - and the cost/benefit of the "one size fits all" single GAAP framework that currently exists. Financial statements for public companies must meet the needs of a disparate user group of investors and creditors with no direct access to financial information other than that which is presented in audited GAAP financial statements. The user group for private companies is smaller and in direct contact with owner/managers. It consists primarily of lenders, vendors, and potentially venture capitalists when the enterprise seeks other financing sources. This user group does not include far flung stockholders whose only interest is in stock market performance.

The argument for relevance is an argument for one of the primary qualitative characteristics of financial statements. It is a two-sided argument. Financial statements should contain information that is relevant to decision making. The implicit argument for relevance suggests that requiring information that is not relevant (i.e., lists of 
items that have been omitted for GAAP compliance; measurement rather than disclosure of certain items such as pensions; etc.) may overburden and mislead decision makers.

High costs appear to be associated with several standards related to measurement and recognition of some items that are also complex and may not be relevant for users of financial statements of private enterprises. These include but are not limited to earnings per share, fair value accounting and asset impairment, deferred taxes, segment reporting, and pension costs. An implicit cost to private enterprises that present audited financial statements that contain exceptions to GAAP when complex, irrelevant items are omitted, is the resulting qualified opinion that may or may not be understood by a lender.

Standard setters abroad have been more pro-active than US standard setters. Accounting standard setters elsewhere chose to accept either a 3-tier or 2- tier GAAP framework or a single GAAP framework with exceptions for private companies several years ago before the IFRS drafted its standards for SMEs. The IFRS developed a set of standards for small and medium sized enterprises (IFRS for SMEs) distinct from standards for public companies in 2009. These standards are being examined by standard setters in Canada, the UK, Ireland, and the EU/EEA countries for smooth integration with their current framework: whether 2-GAAP or single GAAP with exceptions.

It is striking that US standard setters have agreed to work with the International Accounting Standards Board (IASB) to create and accept a set of standards for large publicly traded companies that are universally acceptable (IFRS) yet the FASB has not agreed to accept the IFRS for SMEs. Perhaps the question that should be asked is whether size is the appropriate measure for requiring a single set of standards or whether non-public accountability is the a significant distinguishing characteristic that should lead to a simplified set of standards for financial statements, where non-public accountability is the accepted definition of a private enterprise? This would relieve private enterprises in the US of burdensome and costly requirements that may include irrelevant information and relieve them of the risk of receiving qualified audit reports. It would also protect decision makers without direct access to company managers here or abroad by requiring one size to fit all enterprises that participate in US financial markets.

\section{CONCLUSIONS}

We have presented a history of the debate on Big GAAP/Little GAAP in the US since 1972 by practitioners, users, academics, and standard setters. Big GAAP/Little GAAP has been the topic of several high level studies in the US and in other countries as well. Our discussion has included arguments on both sides of the debate and the results of studies done. We have also examined efforts in the international community to resolve similar issues.

The debate regarding Big GAAP/Little GAAP has produced three possible scenarios for final resolution: a single GAAP framework for all entities both public and private; a 3- or 2- tier GAAP solution involving two or three GAAP frameworks, one for public and one for private entities; and some combination of these two extremes that modifies the single GAAP framework by providing exceptions for private entities. Under the combination approach, private entities would have the option of providing financial statements under GAAP with exceptions for measurement and disclosure yet receive unqualified opinions if their financial statements are fairly presented within the modified framework.

The Financial Accounting Foundation (FAF) appears to be taking another position. By creating the Private Company Standards Improvement Council (PCSIC), they propose to continue to study the issue. The PCSIC would be charged with developing criteria to make determinations about whether and when exceptions or modifications to existing US GAAP for private companies would be allowed. Their criteria and any exceptions they propose to GAAP would be submitted to the Financial Accounting Standards Board (FASB) for approval. The PCSIC would essentially be on probation and continue to work with FASB's approval throughout its existence despite research that shows clearly where exceptions or modifications can or should be made.

We recognize that the issue of standards containing exceptions to issues that are complex and irrelevant to enterprises that are non-publicly accountable (i.e., private companies) has been studied for almost four decades. We 
do not believe more research to determine whether private companies and users would benefit if exceptions to irrelevant standards were permitted is necessary. This question was settled in other countries 10 years ago and those countries are now moving to bring those standards into conformity with SMEs to IFRS for SMEs. US standard setters should do the same: accept IFRS for SMEs.

\section{SUGGESTIONS FOR FUTURE RESEARCH}

Future studies can determine the impact of implementing IFRS for SMEs in those countries that adopt these standards for non-publicly accountable enterprises. It is also warranted to analyze the potential consequences of the FAF proposals and the stand of the AICPA that may lead to two competing standard setters for private companies.

\section{AUTHOR INFORMATION}

Gail B. Wright, DBA, CPA, joined the FGCU faculty as Professor of Accounting in August 2007. She received her doctorate in accounting from the George Washington University in 1985. Previously she taught at the University of Richmond (1983-1994) and at Bryant University (1994-2006). E-mail: gwright @fgcu.edu. Corresponding author.

Daniel P. Fernandez, J.D., is one of Florida's leading water law attorneys and has over 30 years of experience as an environmental lawyer. He has served as chief counsel for the Southwest Florida Water Management District and Staff Director for the Florida Senate Natural Resources Committee, as well as legal counsel for Fortune 100 companies. He was previously an adjunct professor of Business Law at Stetson University and is currently an Assistant Professor of Business Law at FGCU. E-mail: dfernandez@fgcu.edu

Jeremy Burns was born and raised in Florida where he received his B.S. in Marketing from FGCU. While working as a Marketing Client Services Manager he found a passion for financial analysis. Upon completion of his M.B.A. in Finance, he worked in the banking industry as a Financial Analyst. After learning firsthand the accounting practices of banks, he left banking to pursue a career in accounting and received a M.S. in Accounting and Taxation from FGCU. Currently, he is an auditor and tax professional with the national CPA and financial services firm, LarsonAllen in Fort Myers. E-mail: jburns@larsonallen.com

Ryan Hawkins is from Madison, Wisconsin. He received a BA in Economics from the University of Iowa and BS and MS in Accounting from FGCU. Some of his past work experience includes working for the Wisconsin Housing and Economic Development Authority (WHEDA) where he worked in the economic development department. Currently Ryan is working for the CPA firm SVA in Madison, WI and is an auditor specializing in real estate and non-profit accounting. E-mail: ryanhawkins7@gmail.com

Christina Hornsby was raised in Florida. She received her BS in Accounting from Florida Gulf Coast University. After working in the retail industry for a number of years, she left to pursue a career in public accounting. She currently works as an Associate Accountant at Hill, Barth \& King, LLC doing both tax and audit work. She is enrolled as a graduate student at FGCU. E-mail: cnhornsb@eagle.fgcu.edu

Sunny Patel was born and raised in Florida. He has a MS in Accounting and Taxation from FGCU as well as a BBA in Finance from Florida Atlantic University. He has done internships at Cypress Financial, an Office of Met Life in Fort Lauderdale, FL, doing client portfolio management and at Briers CPA, in Bonita Springs, FL preparing tax returns and doing tax research. He is working as a staff accountant for Goal Financial in Alexandria, VA outside the DC metro area. E-mail: sunnypate12005@yahoo.com

\section{REFERENCES}

1. AICPA. (October 2011). AICPA Council Votes Overwhelmingly to Send a Strong Message to FAF: Adopt the Blue Ribbon Panel Recommendations for an Independent Board. http://www.aicpa.org/press/pressreleases/2011/pages/adopt-blue-ribbon-panel-recommendations.aspx

2. Arnold, J., Hope, T., Southworth, A. and Kirkham, L. (1994) Financial Accounting, 2nd edition, Prentice Hall. 
3. Arnstein, P. (December 1972) Unaudited Financial Statements: a Cloud of Dissent. Journal of Accountancy, 81-83.

4. Block, M. (July 1974) Duality in the Accounting Profession. The CPA Journal, 29.

5. Block, M. (March 1977) Trend to Duality in Accounting Standards. The CPA Journal, 11-15.

6. Blue Ribbon Panel on Standard Setting for Private Companies. (January 2011). Report to the Board of Trustees of the Financial Accounting Foundation.

http://www.aicpa.org/interestareas/frc/accountingfinancialreporting/pcfr/downloadabledocuments/blue_rib bon_panel_report.pdf

7. Campbell, J. E. (1984). An Appliction of Protocol Analysis to the 'Little GAAP' Controversy. Accounting Organizations and Society, 329-342.

8. Carsberg, B. V., Page, M. J., Sindall, A. J. and Waring, I. D. (1985) Small Company Financial Reporting, London: Prentice Hall International.

9. Falk, H., Gobdel, B. C., and Naus, J. H. (October 1976). Disclosure for Closely Held Corporations. Journal of Accountancy, 85-89.

10. Feltham, G., and Mathieu R. (September 2000). GAAP for the Little Guy. CGA Magazine, 48-49.

11. Financial Accounting Foundation. (October 2011). Request for Comment: Plan to Establish the Private Company Standards Improvement Council. http://www.accountingfoundation.org/cs/ContentServer?site=Foundation\&c=FAFContent C\&pagename=F oundation\%2FFAFContent_C\%2FFAFNewsPage\&cid=1176159215626

12. Financial Accounting Standards Board. (September 2010). Statement of Financial Accounting Concepts No. 8: Qualitative Characteristics of Useful Financial Information.

13. Fitzpatrick, M. and Frank, F. (December 2009). IFRS for SMEs: the Next Standard for U.S. Private Companies? Journal of Accountancy, 50-54.

14. Grusd, N. (August 2006). On Big GAAP Versus Little GAAP. The CPA Journal, 6-7.

15. Grusd, N. (July 2011) A Lender's Dissenting View. The CPA Journal, 6-10.

16. Herman, N. (December 2010). IFRS for SMEs: Not for Private American Companies. The CPA Journal, 11-12.

17. Institute of Chartered Accountants, New Zealand. (1994, 2007). Framework for Differential Accounting. http://www.google.com/url?sa=t\&rct=j\&q=\&esrc=s\&frm=1\&source=web\&cd=1\&ved=0CBsQFjAA\&url= http $\% 3 \mathrm{~A} \% 2 \mathrm{~F} \% 2 \mathrm{Fwww} . n z i c a . c o m \% 2 \mathrm{FTechnical-and-business} \% 2 \mathrm{FFinancial}-$ reporting $\% 2 \mathrm{FStandards-and-}$ guidance $\% 2 \mathrm{~F} \sim \% 2 \mathrm{Fmedia} \% 2 \mathrm{FNZICA} \% 2 \mathrm{FDocs} \% 2 \mathrm{FTech} \% 2520 \mathrm{and} \% 2520 \mathrm{Bus} \% 2 \mathrm{FFinancial} \% 2520 \mathrm{reporti}$ ng\%2FFRS\%2FFRSs \%2520\%2520SSAPS\%2FFramework\%2520for\%2520differential\%2520reporting.ash x\&ei=FI21TsTcJJKRgQefm9iwBA\&usg=AFQjCNHU109wvOyijcdyEQ3ZpZVQ7VPINQ

18. Jamal, K., Bloomfield, R., Christensen, T. E., Colson, R. H., Moehrle, S., Ohlson, J., Penman, S., Stober, T, Sunder, S. and Watts, R. L. (July 2009). A Perspective on the Canadian Accounting Standards Board Exposure Draft on Generally Accepted Accounting Principles for Private Enterprises. Accounting Horizons, 129-137.

19. Kamnikar, J. A., Kamnikar, E. G., and Burrowes, A. (January 2012) One Size Does Not Fit All. The CPA Journal, 46-49.

20. Love, V. J. (February 2011). Private Company Accounting: a Concept Whose Time Has Come. The CPA Journal, 16-18.

21. McAleese, G. (2000). FRSSE: The Solution to Accounting for Small Companies? Dublin: Dublin City University.

22. Naus, J. H., McGill, B., and Arnstein, P. (January 1974). Practitioner's Forum: Unaudited Financial Statements Revisited. Journal of Accountancy, 77-80.

23. Seifert, D. I. and Lindberg, D. I. (May 2010). Key Provisions of IFRS for Small and Medium-sized Entities. The CPA Journal, 34-37.

24. Stahlin, P. V. (July 2011) 'One-Size GAAP Does Not Fit All, The CPA Journal, 6-10.

25. Zanzig, J. S., \& Flesher, D. L. (2006, May). GAAP Requirements for Nonpublic Companies New Views on 'Big GAAP' Versus 'Little GAAP'. The CPA Journal, 40-44. 


\section{NOTES}

